\title{
"A GENTE NÃO PODE FAZER NADA, SÓ PODEMOS DECIDIR SABOR DE SORVETE". ADOLESCENTES: DE SUJEITO DE NECESSIDADES A UM SUJEITO DE DIREITOS*
}

\author{
JORGE LYRA ** \\ Benedito MedRado \\ Pedro Nascimento \\ Dolores Galindo \\ Maristela Moraes \\ Cláudio Pedrosa
}

\begin{abstract}
RESUMO: Em nossa sociedade, percebe-se um crescimento da preocupação com a adolescência, sendo esta última representada não apenas como uma "fase da vida", mas um período, a priori, sempre problemático. $\mathrm{O}$ adolescente, por sua vez, tem sido visto como um sujeito de necessidades, por exemplo, de um atendimento de saúde específico. Na prática, entretanto, pouco se tem trabalhado com o adolescente como sujeito de direitos, a despeito do debate em torno do Estatuto da Criança e do Adolescente. Com base na crítica a esta postura, o presente artigo tem como objetivo apresentar uma experiência de pesquisa-intervenção de educação nãoformal com um grupo de adolescentes de camadas baixas, na qual se procurou discutir noçôes correntes de adolescência, possibilitando um mapeamento e uma (re)construção de outros sentidos.
\end{abstract}

Palavras-chave: Adolescência. Juventude. Pesquisa. Intervenção.

Educação não-formal.

\footnotetext{
* Uma versão anterior desse texto foi apresentada no IX Encontro de Ciências Sociais Norte-Nordeste, em Natal (RN), de 11 a 13 de agosto de 1999, no GT "Cultura e juventude”. Gostaríamos de agradecer as contribuições de Karla Galvão; Kaliani Rocha; Maria do Carmo Adrião; João Bosco Junior; Adriano Silva; Luciana Leão; Nara Vieira; Sibelle Barros e a todos que fazem o PAPAI.

* Todos os autores são membros do Programa Papai da Universidade Federal de Pernambuco (UFPE). E-mail: papai@npd.ufpe.br. Site: http://www.ufpe.br/papai
} 


\begin{abstract}
"WE CAN'T DO NOTHING BUT DECIDE ICE CREAM FLAVORS". ADOLESCENTS: FROM SUBJECT OF NECESSITIES TO SUBJECT OF RIGHTS
\end{abstract}

ABSTRACT: Our society shows an increasing concern for adolescence, which is represented not only as a "phase of life", but also as a period that is always problematic. Adolescents, as for them, are considered as subjects of such necessities as specific health aids. In practice, however, very little has been done for adolescents as subjects of rights, in spite of the debate about the Statute of Children and Adolescents. Based on a criticism to this position, this paper aims at presenting an experience of research intervention in non-formal education with a group of low-class adolescents, in which we intend to discuss the current notion of adolescence, allowing a kind of identification and (re)construction of other meanings.

Key words: Adolescence. Youth. Research. Intervention. Non-formal education.

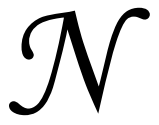

os dias de hoje, convivemos com a idéia de um sujeito responsável pelo gerenciamento do seu presente e futuro, responsável por seus projetos, cada vez mais individualizado, dimensionado como decorrente de escolhas pessoais. Se, por um lado, cresce essa responsabilização pela felicidade (ou infelicidade), por outro, multiplica-se o leque de alternativas possíveis: são múltiplos os perfis identitários delineáveis (Melucci, 1997).

No seio da sociedade contemporânea, a adolescência emerge como um período da vida revestido de interesse e passa a ser compreendido como uma época áurea caracterizada pela possibilidade de trânsito maior em relação aos códigos rígidos do moralmente louvável e do moralmente condenável. Essa é, sem dúvida, uma retórica que pode ser encontrada nas propagandas dirigidas ao jovem e divulgadas pelo mass media: ser jovem é liberdade, vigor, ousadia, estando estes geralmente ligados à cultura e comportamento (Abramo, 1997).

Paralela a essa exaltação da juventude, há também toda uma retórica do medo, da violência, do horror diante de uma juventude vista como um problema social: é a lógica dos números freqüentemente balizada pela voz de especialistas. Este sentimento de insegurança inspirado pelos jovens, como assinala Maugner (1991, apud Peralva, 1997, p. 19), "não pode ser reduzido a um efeito mecânico do crescimento da delinqüência juvenil, (...) lança raízes mais amplamente no conjunto de representações sociais que cada sociedade e cada época constroem sobre sua própria juventude". Se essas 
duas visões extremas podem ser identificadas, outros repertórios também se delineiam em meio a esses.

De fato, pode-se constatar um painel multifacetado de explicações sobre a natureza, gênese e função da adolescência e juventude. Cronologicamente, a adolescência constitui o período imediatamente anterior à juventude, constitui também um período de interface com a infância. Entretanto, no campo dos sentidos, a adolescência pode ser desprendida do orgânico, através de uma maior ênfase no tipo de experiência que a caracteriza do que propriamente no significante biológico/cronológico. Torna-se possível, por exemplo, falar de um prolongamento da juventude metaforizado nas expressóes "adultescência", "geração canguru" ou "pós-adolescência".

Falar em adolescência implica, de certo modo, uma referência ao biológico, mas parece-nos que na experiência atual refere-se, sobretudo, ao campo dos sentidos dessa experiência contemporânea, de um certo modo de subjetivar-se. É um fato que no mundo moderno esta fase alcançou um status de realidade: uma experiência a ser vivida por cada sujeito sem que este possa evitá-la ou manter-se nela pelo tempo que desejar. A adolescência é percebida como uma cena crucial na construção das narrativas pessoais. Naturaliza-se a adolescência como um período essencial para o crescimento do indivíduo e para alguns sociólogos, de linha mais evolucionista, essencial para o desenvolvimento da sociedade, na medida em que os jovens constituiriam focos de mudança, de alterações no status quo.

Grande parte das políticas públicas direcionadas aos jovens parece estar apoiada nessa retórica que ressalta a ameaça representada pela juventude, com constante reforçamento da idéia do jovem como exposto a uma série de riscos próprios a sua fase, os quais podem ser internos (crise identitária) ou externos (violência).

Em linhas gerais, circulam no cotidiano contemporâneo idéias sobre adolescência e juventude que se associam à noção de crise, desordem, irresponsabilidade, enfim, problema social a ser resolvido, que merece atenção pública. Assim, o enfoque de risco, em particular, aparece fortemente associado a esses repertórios, por meio de expressões como: gravidez de risco, risco de contrair o HIV, risco de uso de drogas ilícitas, risco de vida frente à violência. $\mathrm{O}$ risco generalizado parece, assim, definir e circunscrever negativamente esse período da vida, possibilitando a construção de expressões absurdas como a própria prevenção da adolescência (Medrado \& Lyra, 1999). 
Como analisa Abramo (1997), a maior parte dos programas toma os jovens como problemas sobre os quais é necessário uma ação para reintegrá-los à ordem social, por meio de estratégias como ressocialização, capacitação profissional, ou de uso do "tempo livre".

Não podemos negar os dados epidemiológicos, mas tão somente mostrar como vai se construindo a noção do adolescente como um sujeito permanentemente em risco, submetido a uma condição especial. Se tal concepção pode por um momento ser aceita sem maiores implicações, um de seus reversos deve ser alvo de atenção - a construção do adolescente como um sujeito de necessidades definidas em relação a um estado ótimo, que parece ser a fase adulta, descrita constantemente como o ápice do desenvolvimento humano. É interessante que ninguém tenha ainda tentado tecer uma história dos adultos. Se esta é uma referência forte para definir e valorar qualquer etapa da vida, parece não ser suficiente para abarcar a definição de uma historicidade própria.

Cria-se, assim, uma relação lógica de causa e efeito: se o adolescente é uma fonte potencial de problemas sociais e um risco constante a si mesmo e à sociedade, torna-se preciso prevenir a sua exposição a determinados fatores, como, por exemplo, a gravidez. Indo mais a fundo, vê-se subliminarmente a emergência de um discurso heteronômico no qual o(a) adolescente é desprovido(a) ${ }^{1}$ de sua positividade, em detrimento de um padrão que tem como referência a vida adulta. Por um malabarismo retórico termina-se por quase se afirmar que é preciso prevenir a adolescência, tal qual concluem ironicamente Medrado \& Lyra (1999) que, tomando a gravidez na adolescência como objeto de análise, afirmam: "não nos surpreenderia se um dia ouvíssemos em uma palestra ou lêssemos em um projeto de pesquisa e/ou intervenção a expressão prevenindo a adolescência" (p. 230).

Com o devido recorte, não se está fazendo uma crítica generalizada a trabalhos junto a adolescentes, mas tão somente buscando assinalar premissas problemáticas que podem conduzir a ações ou diretrizes distorcidas no que tange à população adolescente, podendo vir a resultar em ações de pouca efetividade e que, de certa forma, podem auxiliar a perpetuação desse modelo.

Antes de qualquer consideração, configura-se essencial presentificar o adolescente como sujeito dotado de uma positividade. Ao se pensar em qualquer programa de ação direcionado a essa população, cabe investigar o modo como experimentam e interpretam essas si- 
tuações problemáticas (Abramo, 1997), deixando claro que fazê-lo não é somente criar um espaço-simulacro no qual a fala do adolescente e do profissional reifiquem o que já se quer dizer ao primeiro, sendo, portanto, mais um espaço de reprodução social, e não de construção de um espaço de diálogo, condição sine qua non para o protagonismo juvenil.

Para falarmos de uma positividade do adolescente, cabe-nos caminhar na direção de uma tendência oposta vinda dos próprios jovens que, recentemente, têm-se organizado em fóruns especiais; seja em lutas contra o status quo, seja em favor de ideais conservadores. Movimento esse endossado pelo Estatuto da Criança e do Adolescente (ECA) e de todos os fóruns de discussão feitos em torno dele. Verifica-se a existência de movimentos feitos por jovens objetivando mudanças mais amplas, em contraponto à irresponsabilização atribuída ao adolescente. Entretanto, estes movimentos, como assinala Melucci (1997), aparecem dissolvidos em meio à combinação de diversos outros fatores - pobreza, desemprego, imigração -, não havendo ainda um espaço para que as vozes juvenis sejam ouvidas.

A partir dessas reflexões, em nosso programa de intervenção tomamos como princípio ético o respeito às jovens geraçôes, expresso através da criação de um espaço de acolhimento e exercício de autonomia e responsabilidade. Isto feito a partir de uma lógica baseada na acepção de um sujeito capaz de pôr a própria noção de adolescência na arena das possíveis ressignificações, no campo de uma ação propositiva. Trata-se de um espaço no qual a noção de um sujeito de direitos não aparece definida em função da heteronomia, numa perspectiva homogeneizante, mas ao contrário, incorpora a alteridade como valor fundamental (Sawaia, 1994). Sujeitos que podem efetivamente "contribuir para a solução dos problemas sociais, além de simplesmente sofrê-los ou ignorá-los" (Abramo, 1997, p. 28), por meio da criação de um locus de enunciação juvenil.

Nessa coletânea, temos como objetivo apresentar uma experiência de pesquisa/intervenção, realizada com um grupo formado por adolescentes atendidos pelo Núcleo do Programa de Saúde do Adolescente (Prosad) ${ }^{2}$ no Hospital das Clínicas da Universidade Federal de Pernambuco. Como proposta de atuação, essa atividade está inserida num plano de ação mais amplo, desenvolvido no Programa PAPAI, que visa trazer para primeiro plano de discussão a importância da participação jovem e masculina no campo das relaçóes de gênero, sexualidade e reprodução. 
Essa experiência de intervenção foi considerada dentro de uma lógica institucional, que visa uma interlocução entre as áreas de pesquisa, ensino e extensão, apontando algumas indicações para outros trabalhos junto a esta população. Nesses grupos de adolescentes, buscamos construir um espaço no qual discutimos noçóes correntes de adolescência e questôes relativas a essas noçôes, permitindo a construção dialógica de novos/outros sentidos.

O trabalho de intervenção foi subdividido em algumas fases: (1) negociação da proposta com instituição conveniada; (2) recrutamento dos jovens; (3) formação do grupo; (4) reunião com pais/responsáveis; (5) desenvolvimento das atividades em grupo; (6) avaliação da atividade junto à equipe/profissional da instituição parceira e (7) sistematização da experiência. Além disso, a atividade em grupo foi intercalada por reuniōes de avaliação e planejamento, subsidiadas pelas avaliações feitas pelos integrantes da equipe e pelos registros feitos de cada encontro.

Os membros da equipe técnica ${ }^{4}$ de intervenção alternavam-se nas funções de: coordenador - responsável pela condução do encontro como um todo; observador - encarregado de fazer o registro das atividades desenvolvidas, estando atento às facilitações feitas pela equipe e aos movimentos do grupo; facilitador - compreende a atuação mais centrada diretamente na condução das atividades do grupo.

Cada encontro foi subdividido em quatro etapas: 1. abertura - aplicação de recurso técnico para possibilitar um movimento de introduzir o grupo no sentido da temática a ser abordada; 2. recurso expressivo - aplicação de uma técnica na qual buscamos apreender vivências/experiências pessoais e sociais dos membros do grupo; 3. discussão - confrontação das idéias do grupo com maior centralidade nos pontos-chave a serem alcançados no dia; avaliação - cada participante, incluindo a equipe, apresenta os pontos mais importantes do dia, sugestóes e pontos negativos; 4. fechamento - recurso técnico aplicado ao grupo com o objetivo de concluir a atividade do dia, reforçando pontos necessários, seja do ponto de vista temático, seja do ponto de vista da dinâmica sócio-afetiva.

O grupo iniciou suas atividades no dia 5 de abril de 1999 e encerrou em 7 de junho do mesmo ano, com reunióes semanais com duração de duas horas. Ao todo foram feitos dez encontros, sendo o primeiro formado por adolescentes e pais de adolescentes, os oito seguintes apenas com os adolescentes e o último com os pais destes. Em cada encontro, era abordada uma temática específica de uma 
programação negociada entre a equipe técnica e os adolescentes no segundo encontro.

Os temas trabalhados nessa programação foram: adolescência; diálogo com os pais; relacionamentos (amizade, "o ficar", namoro); sexualidade na adolescência (relação sexual, métodos contraceptivos e prevenção de DST/Aids); aborto; drogas e relaçôes de gênero. No último encontro com os adolescentes fizemos uma avaliação geral do processo e uma comemoração de encerramento.

A composição da equipe técnica levava em consideração a base institucional do PAPAI, que entende a estrutura universitária como um locus privilegiado que, por sua natureza institucional mais ampla, permite e facilita a inter-atuação de instâncias que desenvolvem atividades nas áreas de educação, saúde e ação social, de modo a possibilitar um diálogo entre essas instâncias e as perspectivas dos adolescentes.

O grupo de adolescentes era composto por seis integrantes, sendo cinco do sexo feminino e um do sexo masculino, com idades entre doze e dezoito anos. Esse número foi estabelecido só depois do segundo encontro, pois na primeira reunião (no dia 5 de abril) estiveram presentes pais de adolescentes e adolescentes, aproximadamente 40 pessoas. Nessa reunião, em que foi apresentada aos usuários do serviço de saúde a proposta de trabalho, juntamente com os horários disponíveis para a realização dos encontros, a incompatibilidade de horários foi o maior impedimento à participação de muitos interessados.

Num primeiro momento, realizava-se o recurso técnico de abertura, utilizado para chamar os adolescentes para a atividade, preparando o grupo para a temática do dia. Para tal, foram utilizadas técnicas de relaxamento, mímicas e outros jogos lúdicos. Além disso, tal recurso teve, nos primeiros encontros, também uma função integradora do grupo, estimulando a participação dos adolescentes durante o resto do encontro.

Um grupo que a princípio se mostrava receoso e hesitante passou a configurar-se num grupo interativo, dinâmico e cooperativo, e as histórias construídas no dia a dia de cada um começaram a surgir. Sem dúvida que a inibição inicial faz parte do processo de qualquer grupo e que gradativamente vai sendo dissipada, mas podemos apontar o desenvolvimento de uma relação ativa e construtiva entre os indivíduos como o resultado pretendido de uma abordagem planejada. 
Porém, em certas situações o recurso de abertura escolhido não cumpriu o objetivo. Em alguns encontros, o envolvimento buscado não foi alcançado na intensidade pretendida. Aqui aprendemos não apenas a aceitar o momento do grupo, mas a compreender que este deveria ser levado em conta ao escolhermos cada recurso a ser utilizado. Não se tratava mais de pensar na díade tema-recurso, mas numa associação tema-recurso-momento do grupo e nível de mobilização da temática.

Num segundo momento, era aplicado um recurso técnico expressivo com o objetivo de subsidiar uma reflexão ulterior a partir das vivências do grupo. Como técnicas utilizamos recorte/colagem, construção de histórias, encenação e mímica, que obedeciam a um roteiro de tópicos definidos na reunião de planejamento. Atentando-se não somente para o surgimento de questôes propostas pela equipe, como também se conferia atenção às questóes postas no desenvolvimento do recurso.

Um terceiro momento consistia numa discussão despertada a partir do resultado final produzido na técnica expressiva (cartaz, história, mímica, teatro etc.). Neste segmento, tanto eram trabalhados tópicos provenientes dos discursos dos adolescentes como também eram trazidas informações adequadas à temática do dia.

À medida que as histórias sociais e pessoais de cada um vinham à tona, traziam com elas as diferenças e, com estas últimas, o conflito. Nós da equipe, de certa forma, pretendíamos que algo acontecesse, para que se pudesse tornar explícito o conflito de valores implícito na relação do grupo, visando com isso colocar em debate as concepções hegemônicas que os próprios adolescentes acreditam, e que também têm possibilidades de ressignificá-las.

Ao final do grupo, realizou-se uma reunião com os pais/responsáveis com a temática "adolescências", na qual pudemos rediscutir com os pais as concepções utilizadas por eles em sua vida diária, e como essas concepções se estruturam ao longo de suas biografias em relação com a história social a que pertenciam e como orientam suas condutas na relação familiar.

Problematizando a experiência: a possibilidade de ações propositivas

Viabilizar a experiência de intervenção implicou atuar em meio a um conjunto de discursos que, mesmo heterogêneos, convergiam 
para uma concepção do adolescente como vítima - dos hormônios, da imaturidade, da falta de serviços - da própria adolescência. Realizar o trabalho com o grupo implicou, assim, um processo de negociação junto aos profissionais.

Nas primeiras reunióes com a equipe do núcleo do Prosad, era clara uma posição medicamentosa explicitada pela definição do adolescente como um sujeito instável, para o qual questôes como gravidez e sexualidade mereciam atenção redobrada, com o fim de evitar uma gravidez precoce, por exemplo. Assim, tinha-se por parte da instituição uma solicitação de atuar no sentido de prevenir que esses adolescentes se tornassem um problema social, a partir de uma situação de diálogo. Desse modo, o primeiro momento consistiu em criar junto com os profissionais desse núcleo uma outra perspectiva sobre a adolescência, a fim de possibilitar a efetivação do trabalho.

Implicou também trabalhar as formulaçôes e posicionamentos enunciados pelos pais/responsáveis. Estes, de certo modo, pareciam também esperar um outro tipo de trabalho de cunho psicoterapêutico ou de orientação diretiva, explicitado no desejo de que "eles [os adolescentes] tenham alguma orientação", de que "possam conversar porque são muito problemáticos, agressivos" e não sabem como lidar com o adolescente porque hoje estão cada vez mais "difíceis". Uma das mães enunciou: "certos filhos insistem em fazer coisas erradas".

Uma das mães, inclusive, compareceu ao segundo encontro destinado apenas aos adolescentes, intervindo no sentido de mostrar que a filha estava ali "porque toma remédio", já que "o diálogo em casa existe". Ao que ela responde que "é... vai melhorar essa fase que eu tô passando". Assim, vê-se que o espaço de diálogo se afigura para aquela mãe como instaurado por uma ausência do mesmo no espaço familiar e nunca um espaço definido em função de uma ação propositiva do/a adolescente.

Significou trabalhar, junto aos adolescentes, a perspectiva de que não se trata de um grupo terapêutico, nem uma exposição de conteúdos, mas um grupo para discutir temas de interesse relacionados, direta ou indiretamente, à vivência da adolescência.

Estes saberes diferenciados não foram anulados no contexto interacional do grupo. Estiveram presentes nas falas, nas práticas e nas intervenções demandadas. Partimos da compreensão de que, independente dos sujeitos envolvidos, todo olhar mais atento, de perto, com 
a intenção de respeitar os pontos de vistas alheios e, na medida em que isto é possível, o distanciamento de nossos preconceitos e opiniões formadas, fará sempre entrever realidades até então impensadas e, quando não tanto, ao menos a elucidação de suposições.

\section{Saberes e poderes: negociando sentidos com os(as) adolescentes}

A própria existência desta experiência só foi possível pelo fato de duvidarmos das opinióes correntes acerca desta "fase da vida". A existência do PAPAI está motivada, em grande medida, pela crença de que não apenas estas são equivocadas, mas que, mais ainda, podem e precisam ser modificadas. Sendo assim, pôde-se perceber os adolescentes com quem convivemos como sujeitos de direitos e deveres, imbuídos de um forte sentido de autonomia e que, por isso mesmo, são capazes, como todos os sujeitos, de manipular suas identidades e discursos de acordo com seus interesses e contextos diversos.

Esta é a questão que estamos trazendo à tona. A visão tradicional do adolescente como um ser dependente, um "sujeito de necessidades" vivendo a eterna crise de não-ser-mais-criança-e-aindanão-ser-adulto, talvez fale muito mais dos que a construíram do que dos próprios adolescentes. No entanto, essa visão é, muitas vezes, acionada de acordo com a questão que está sendo posta em jogo: mesmo assumindo o estereótipo, eles o negam. Em outros momentos, a clareza com que eles interpelaram certas questôes postas por nós, deixando-nos, às vezes, embaraçados, faz também entrever uma postura ativa, que visões cristalizadas não permitiriam notar que certas atitudes eram expressões de vozes discordantes do que está posto.

Em determinada situação, quando estávamos criando conjuntamente uma história cujo tema eram as relações de namoro e amizade, pudemos perceber um grande número de opiniões que se opunham, cada um dos adolescentes buscando fazer com que o seu ponto de vista prevalecesse. $O$ próprio fato de perceber o grupo de modo heterogêneo, por várias vezes fazendo surgir conflitos, é um elemento importante para o propósito de problematizar uma visão homogeneizante do adolescente marcada pelo estereótipo.

Duas integrantes do grupo, que eram amigas mesmo antes da formação do grupo, em várias situações marcavam suas opiniōes sempre em oposição a uma terceira. Enquanto esta se anunciava sempre dentro de um discurso "moderno" e "livre", onde dizia fazer sempre 
o que queria, sem maiores interferências dos pais e mostrava-se favorável a questóes como sexo antes do casamento, passar a noite fora de casa etc., as duas primeiras anunciavam um discurso que chamaríamos de "conservador" e sempre apresentado como condicionado pelas opinióes e o controle dos pais. Demonstrando mesmo "aversão" a certos comportamentos ou falas da outra integrante.

Numa discussão sobre namoro, quando suas idéias destoaram significativamente, intervimos colocando: "o que fazer diante da diferença de opinióes?” Fomos mais além, perguntamos o que cada uma delas sentia em relação à divergência da adolescente em questão e o que a própria pensava. Depois disso, o grupo obteve um melhor fluxo de comunicação e ela foi “integrada”. Não pretendíamos com esta ação negar as divergências, ou suprimir os conflitos do grupo, mas viabilizar um maior diálogo entre todos os integrantes. A importância do mesmo está em sugerir a diversidade de pontos de vista que são recobertos pela mesma noção de adolescência.

Em nível diferente, mas igualmente apontando para a existência de adolescentes sujeitos, podemos pensar sobre como, em algumas situações, estes operavam uma certa manipulação de identidades a partir do mesmo repertório de estereótipos com que são percebidos. Como pontuamos acima, uma das mais veiculadas imagens acerca dos adolescentes é a de que eles vivem num limite sempre mal definido entre a infância e a fase adulta e que, por isso, enfrentariam profunda crise de identidade e falta de clareza acerca de seus posicionamentos, aspirações e projetos. Em outros termos, falta-lhes autonomia. Esta situação os impeliria a comportamentos transgressores, rebeldia, pouca adequação às regras e, face ao controle dos adultos, uma constante busca por emancipação e liberdade.

"A gente não pode fazer nada, só podemos decidir sabor de sorvete". Essa fala de uma das adolescentes do grupo remete à insatisfação diante da autoridade dos pais, num momento em que falávamos sobre liberdade e sobre o modo como os pais educam os filhos. Surge aqui um adolescente que quer ser livre para fazer o que quiser, "sem ter que dar satisfação a ninguém", corroborando a idéia da privação, na qual se questiona a autoridade paterna, apontando suas contradições: "Um dia eles deixam, outro dia não deixam e não explicam porque. (...) Um pai deve ter voz firme e não dizer uma coisa e depois outra”. O próprio espaço de discussão foi apontado em momentos de avaliação como uma experiência positiva, exatamen- 
te por constituir um lugar de liberdade que o ambiente doméstico não proporcionava.

Porém, em outros momentos, foi possível ouvir coisas do tipo: "Mas a gente deve dar razão aos pais, apesar de tudo". Aparecia a idéia, veementemente reafirmada, das vantagens que podem existir nesta situação. Possivelmente, isto se deve ao fato de que ninguém queria passar uma imagem negativa de suas famílias, ou de seus pais, mas remete também ao fato de que, não apenas se tem consciência da estrutura das relaçōes de poder em que se vive, mas que as mesmas são resignificadas de acordo com os interesses em jogo. Ou seja, em alguns momentos, o discurso de necessidade de emancipação e busca de liberdade é acionado, fazendo perceber a assimetria geracional, mas esta mesma assimetria é configurada positivamente quando se ressalta a importância de se ter alguém "que cuida da gente" e é responsável por muitas atitudes que podem estar, inclusive, assentadas nesta relação.

É bom ter em mente que essa noção não está querendo remeter a um jovem manipulador ou desproblematizar a situação de subordinação e falta de autonomia dos adolescentes, pelo contrário, o que se está fazendo é alertar para o fato de que apontar esta condição não é qualificar o adolescente como vítima. Além disso, ainda que questionem certas atitudes dos pais: "a minha mãe fuma e bebe, eu não. Se fosse por uma influência...", em outras situações os adolescentes posicionam-se reproduzindo comportamentos dos pais, por vezes contestados: "Acho que quando eu crescer vou ser muito protetora como minha mãe. Vou fazer meu filho sofrer como minha mãe faz".

Em suma, é importante destacar que as análises aqui apresentadas compreendem um processo ainda em fase inicial de desenvolvimento. As consideraçôes por nós levantadas constituem análises exploratórias, que tiveram a difícil meta de propor um constante diálogo entre pesquisa e intervenção social. A experiência com esse grupo foi uma oportunidade para problematizar a visão estereotipada do adolescente como sujeito de necessidades, oferecendo subsídios para ações mais eficazes voltadas para esta população. É importante termos atenção especial para não construirmos, com base em valores dados como naturais, verdadeiros problemas.

\section{Notas}

1. A partir desse momento empregaremos o genérico masculino para nos referirmos aos $\mathrm{e}$ às adolescentes. 
2. O Programa de Saúde do Adolescente (Prosad) é um Programa Nacional do Sistema Único de Saúde (SUS) organizado numa distribuição distrital em núcleos e unidades de saúde pública com base nos princípios da Organização Mundial de Saúde (OMS).

3. O registro constitui um instrumento valioso de avaliação do processo, posto que permite um maior rigor na coleta e análise das informações. Através dos registros foi possível observar a maneira como o grupo operava e seu progresso, permitindo ajustes constantes na proposta em função do andamento do processo.

4. A equipe técnica, no $1^{\circ}$ semestre de 1999 , foi composta por profissionais e estudantes das áreas de Psicologia, Antropologia, Medicina e Enfermagem.

\section{Referências bibliográficas}

ABRAMO, H.W. Considerações sobre a tematização da juventude no Brasil. Revista Brasileira de Educação, Belo Horizonte, n. 5/6, p. 2536, 1997. Número especial.

MEDRADO, B.; LYRA, J. A adolescência "desprevenida” e a paternidade na adolescência: uma abordagem geracional e de gênero. In: Schor, N.; Mota, M.S.F.T.; Castelo Branco, V. (Org.). Cadernos juventude, saúde e desenvolvimento. Brasília, DF: Ministério da Saúde, Secretária de Políticas de Saúde, 1999, p. 230-248.

MELUCCI, A. Juventude, tempo e movimentos sociais. Revista Brasileira de Educação, Belo Horizonte, n. 5/6, p. 5-14, 1997. Número especial.

PERALVA, A. O jovem como modelo cultural. Revista Brasileira de Educação, Belo Horizonte, n. 5/6, p. 15-24, 1997. Número especial.

SAWAIA, B.B. Cidadania, diversidade e comunidade: uma reflexão psicossocial. In: SpINK, M.J.P. (Org.). A cidadania em construção: uma reflexão transdiciplinar. São Paulo: Cortez, 1994, p. 147-156 